sideration. There were no symptoms present at any time to direct attention to the chest-neither pain, cough, dyspnoea, nor expectoration.

The case was a severe and complicated one throughout, all the symptoms were brought on by free living, the jaundice and diarrhoa being the fruits of a troublesome gastro-duodenal and intestinal catarrh.

Listowel.

\section{ON A CASE OF HYDROPHOBIA.}

BY W. MITCHELL ROOCROFT, M.R.C.S., \&c., HONORARY SURGEON TO THE ROYAL ALBERT EDWARD INFIRMARY, WIGAN.

HydRophoBIA being a disease of comparative rarity, I venture to hope that the following notes of a case occurring in my practice may be of interest.

John F-_ aged twenty-eight years, a groom and coachman, was bitten by a bloodhound bitch on June 21st, 1883. He was a steady and temperate man, having previously enjoyed good health, but of nervous temperament. I saw the patient next day. He was suffering from mental anxiety, and had a punctured and lacerated wound on the upper lip, which had been thoroughly cauterised with nitrate of silver by a surgeon, to whom he had immediately hurried upon receipt of the injury. At the urgent request of the patient, I examined the bitch. I found her chained up, and with difficulty induced her to leave the kennel, as she seemed to shun the light, and was dull, but snappish. The coat was staring, and the abdomen tucked up. Appetite was lost, lat evidently she could drink without much difficulty. I detected no modification in the bark, and although her head was depressed, the jaw had not dropped from paralysis. She had bitten fox terrier dog on the previous day. I advised that the animal be removed to an adjoining kennel, where she could be watched and prevented from inflicting further harm, but not to destroy her. Although the synutoms were those of incipient rabies, I was anxious to watch for the full development of the disease. Unfortunately popular prejudice was too strong, and the bitch was shot the same afternoon. The wound on my patient's lip healed completely, and he seemed to regain his usual health, though his friends remarked that at times he was nervous and depressed. On Sunday, July 29th, it was noticed that the patient was peevish, irritable, and low spirited, complaining of alternate chills and heats, with anorexia. It may here be noticed that the period of incubation or "delitescence" was thirty. eight days; in a previous case under my care the limit was from thirty-nine to forty days. I was sent for hurriedly to see the patient on the morning of August 1st. He had passed a very bad night, having had little or no sleep, repeatedly jumping up with what he termed "bad dreams." The stage of "recrudescence," as it has been termed, was rapidly passing away, and I found him in bed with an anxious expression on his face. There was no redness or irritability about the wound, which presented a healthy cicatrix, and I could not detect any affection of the submaxillary, deep parotid, or cervical lym. phatic glands. He complained of a feeling of oppression about the chest, with severe pains in the epigastrium, due, I thought, to spasm of the diaphragm; but upon ausculta tion $\mathrm{I}$ discovered in addition evidence of acute endocarditis, with a mitral systolic murmur. This murmur increased in intensity as the disease progressed. There was no history of a previous attack of acute articular rheumatism. I noticed involuntary deep sighing jnspirations from time to time. Temperature in axilla $1002^{\circ}$. Tongue dry, but clean bowels regular ; complete anorexia; pulse regular, but laboured; face flushed; head hot and aching; only very slight difficulty in swallowing; urine normal, but scanty. I ordered warm applications to the cardiac region and epigastrium, small quantities of strong beef-tea and milk, complete rest and quietness, and the following draught : - Thirty grains of hydrate of chloral, thirty grains of bromide of potassium, half a drachm of tincture of digitalis, in ar ounce of orange water. $\mathrm{He}$ was seen again in the evening, when the symptoms were about the same, but he had had a little sleep, and was quieter; had swallowed a little beef-tea, but was becoming more thirsty. The draught, to be repeated.-August 2od : Much worse since 5 A.M.; no sleep; expression of face intensely anxious and much flushed. Temperature $101^{\circ}$. Is bathed in a profuse perspiration; mitral murmur intensified; pulse weak, and almost uncountable. He cannot now swallow, owing to the spasmodic action of the muscles of deglutition and respiration; in fact, the very sight of water, and his hearing me pour out a draught containing thirty grains of bromide of potassium and half a drachm of tincture of cannabis indicus, was sufficient to bring on a most agonising spasm. These attacks were accompanied by fits of violent mania, during which it was almost impossible to keep him in bed, followed by intervals when the intelleet was quite clear. During these remissions I discovered that when I induced him to shut his eyes he could swallow small quantities of the draught without much difficulty. I now ordered ice-bags to be applied along the spine, the room to be completely darkened, and the bed surrounded by light curtains, for I noticed that hyperæsthesia of the surface and of the special organs was rapidly manifesting itself. $\mathrm{He}$ gradually became worse, and appealed piteously for those in the room not to move or cause any draught, theslightest movement or breath of air being sufficient to bring on most frightful spasms of the muscles of deglutition and respiration, the diaphragm being in a state of intense clonic spasm. Thirst was now most agonising, and his mouth, dry and parched, was constantly filling with viscid, clammy saliva, the efforts to expectorate which only increased the frequency of the spasms. The condition of the patient was rapidly becoming worse, and I felt that the condition of his heart would not justify me in the administration of chloroform by inhalation (a course I adopted in my previous case, but with no better result), so at 11 A.M. I gave half a grain of morphia hypodermically. It was not until twelve o'clock that the morphia had any appreciable sedative effect. The patient gradually sank and died at 1.45 P.M. the same day from syncope. I regret that I was unable to obtain a post-mortem examination of the body.

In conclusion, I may mention that the fox-terrier bitten by the same bloodhound died from acute rabies on the same afternoon as my patient. I am unable to account satisfactorily for the etiology of the acute endocarditis in this case. It may have been merely an accidental coincidence. I am afraid my case only illustrates too painfully our present inability to ward off a fatal issue in this dreadful disease.

Wigan.

\section{AMENORRHGEA DEPENDING ON ABSENCE OF THE UTERUS.}

BY J. L. VAN GEYZEL, M.B., C.M., SURGEON, INDIAN MEDICAL DEYARTMENT.

ThE social consequences to a married Brahmin female of the existence of any bar to pregnancy are, I believe, of a far more serious nalure in India than in any other country in the world. The Brahmin law provides for the perpetuation of families by permitting a man to take a second wife when a first wife has no issue after a reasonable period of married life; this is always taken advantage of, so that it is not difficult to surmise the relative position of the first wife in such a household, where she would be treated as the "waiting maid," if she does not return to her friends to live in disgrace and widowhood. Apart from this interest in a case, where an opinion fraught with such serious consequences should be well considered and weighed, the rarity of the occurrence of instances of absence of the uterus, discovered during life, has induced me to record the following notes of a case which I was asked to see by the civil sur. geon:-

A. B-, a Brahmin female, married, aged twenty years, sought advice on account of sterility, stating at the same time that there was some obstacle to complete sexual intercourse. Previous history as related by the civil sur. geon :-General health has always been good; but she has never menstruated, though since April, 1882, she has experienced, from time to time, symptoms known as "the menstrual molimen." What the consummate ignorance of native hakeems and barber women could accomplish was resorted to before applying for European advice, and she had been advised to try to dilate the uretbra, as the small size of the vagina was thought to be the cause of sterility. By means of pieces of pith she had succeeded in dilating the urethra, and no doubt intercourse took place through 
this passage, till one day (about twelve months ago) she applied at the Civil Dispensary for relief, the piece of pith having slipped into the bladder. The forefinger was easily introduced through the urethra into the bladder, and, by hooking the piece of pith between the flexed joints of the finger, its withdrawal was effected. Beyond slight incontinence of urine for three or four days, nothing of any consequence followed, and she was discharged as well as ever. No farther interference was desired at the time, and none was allowed. Since then she has been much the same as before.

Present state. - She is of middle stature, well-formed, plump, and the possessor of a good female figure, breasts full and round, naturally developed, voice feminine. She experiences distinct fulness of breasts, pain in loins, and feeling of slight malaise for four or five days at regular intervals, varying from twenty-five to twenty-eight days; but she has never had a discharge of any sort at or about these times. Sexual appetite is admitted. On making a vaginal examination the forefinger passed in to about half way between the flexures of the distal and second joints, when its point impinged against a membrane, which could be carried before the point of the finger till the latter entered the vagina to just past the flexure of the second joint (about two inches). Further progress was impossible without using force and causing pain. Now, by carefully sweeping the finger all round, the obstructing membrane was traced to be continuous with the vaginal walls, and a most careful search with the point of the finger failed to discover any trace whatever of an opening. There was no feeling of solidity or fluctuation behind this membrane or anywhere round the vaginal walls. The hand over the pubes failed to detect anything solid between the internal and external fingers, which could meet by pressure over the pubes, The forefinger introduced in to the rectum (previously emptied) failed to find the slightest clue to the presence of the uterus, nor could this method with external abdominal palpation succeed in discovering this organ.

An ocular examination of the external genitals was next made, and the following points noted :-External organs all present; labia not quite fully developed in proportion to the general development of the body ; clitoris small ; the urethral orifice had radiating folds of mucous membrane surrounding it; giving one the idea of there being slight prolapse of this passage; the vaginal orifice was very small, but easily dilatable; no hymen present. A duck-bill speculum was introduced into the vagina as far as it would go, and nothing could be seen except receding and advancing pink walls ending in a blind pouch. With the speculum in situ the finger failed to discover any thing fresh, and no opening could be felt or seen in the terminating membrane or vaginal walls. A sound was next introduced into the bladder and the right forefinger introduced into the rectum, as high up as possible, and by very slightly moving the handle of the sound its tip was felt by the finger quite readily, and the course of the sound in the bladder could be easily made out by continuous contact along it with the rectal finger, till the vaginal culde-sac could be fitt intervening by a feeling of increased thickening of the media between the sound and the finger. $\mathrm{By}$ lateral and antero-posterior movements within the bladder, and side to side in the pelvis, the point of the sound conld be readily reached and its course traced along by the rectal finger, but no intervening solid body, such as any part of the uterus, could be made out. A careful exploration in all directions failed to detect anything like a solid body, large or small, between the bladder and rectum; indeed the great ease with which the sound could be felt in all directions by the finger in the rectum, and the thinness of the interrening media between the metallic sound and the fleshy finger left no doubt as to the fact that the bladder was lying on the rectum without the interposition of anything, except, anteriorly, the vaginal cul-de-sac.

I may add that, with the seriousness of the consequences to the patient before us, the examination was as careful and thorough as posuible, and in order that nothing might be overlooked or mistaken the civil surgeon repeated for himself each step of the examination before going on to the next; and as we were able to agree in every particular in the diagnosis, no doubt was entertained as to its accuracy, and accordingly a decided opinion was given. As the value of the record of such a case as this would be enhanced by the minuteness with which all its particulars were noted, I have endeavoured to detail carefully every step in the process of examination and diagnosis.

Pemarks. - The points involved in the consideration of the diagnosis may be briefly summed up as follow. All cases of amenorrboe $a$ belong practically to one of two classes. Class $A$, where menstruation has never been performed, or only imperfectly. Class $B$, where menstruation has been performed, but has now ceased or is irregularly performed. The present case of course belongs to Class $A$, and the various causes considered likely to give rise to this class of cases are briefly:-1. Causes obstr ucting the flow of menstrual discharges chiefly: $(a)$ imperforate hymen; $(b)$ occlusion of vagina ; $(c)$ occlusion of os uteri. 2. Causes depending on absence or imperfect development of : $(a)$ ovaries ; $(b)$ uterus. 1. There were no signs of obstruction to the menstrual flow present; abdomen was of natural size, and manual examination was easily conducted, as the abdominal walls gave readily on pressure, and pain of any sort was absent. No signs of accumulation of menstrual discharge could be made out per rectum, per vaginam, or by palpation. (a) The obstructing membrane was too far in for a hymen, and it was clearly the end of the cul-de-sac. The hymen was absent, as intercourse was practicable. (b) Absence of a history of previous vaginal inflammation-idiopathic, traumatic, or post-partum-tells against vaginal occlusion by adhesion \&c. ; and as to sloughing and adhesion of the parts in early life, occlusion resulting from this state of matters is usually met with at or near the vulva, while in the present case there was no obstruction till the finger passed in about two inches. (c) No os uteri could be felt or seen, and if one existed at all, the os would be behind the cul-de-sac, and if occlusion of the os were still present under these circumstances, signs of accumulation of menses within the uterns would be present, which, I need hardly add, was not the case.

2. (a) As to the condition of the ovaries a fair guess may be allowed. The presence of menstrual molimina since April last year, with natural development of the figure and breasts, and the existence of sexual desire, point to the inference that the ovaries are present, and most probably in an imperfectly developed condition; and as she has lived with her husband for the past three years, and menstrual molimina have appeared during the last fourteen months, it is also reasonable to suppose that sexual intercourse has acted as an ovarian stimulus. (b) By exclusion the last cause referring to the uterus itself is arrived at. The validity of this is supported by there being no uterus felt at the end of the vagina, and no trace of it being discoverable by bimanual examination, per rectum, per vaginam, or per rectum et vesicam. The uterus may, of course, be present in an extremely rudimentary condition, in the form of a small collection of non-striated muscular fibres between peritoneal folds, and fail to be discovered by the methods of examination available in a living subject; but the facts viewed together, that the vagina is shorter than natural, and ends in a cul-de-sac, that the external genitals are disproportionately small, that strong presumptive evidence exists of an imperfectly developed condition of ovaries, and that the uterus is not discoverable on carefal examination by the methods at our disposalthese facts combined form, at least for all practical purposes, a chain of strong evidence that the uterus is absent.

\section{EXOPHTHALMIC GOITRE：CURE.}

By EDWIN PAYNE, M.D., M.R.C.P. LoND., PHYSICIAN TO THE MARGARET-STREET INFIRMARY FOR CHEST DISEASE.

From February to September 28th, 1882, I attended, in conjunction with Dr. T. S. Byass, a young lady, aged twenty-five, suffering from exophthalmic goitre. The eyes were very prominent. The whole of the thyroid gland was very much enlarged, especially on the left side. There was excessive overaction of the heart, and for about two months it presented physical signs of enlargement, and particularly its apex beat was to be noticed a little to the left of the nipple. There were abnormal sounds, diastolic and systolic, both at the mitral and aortic valves, of a soft, rushing character, and violent beating of the carotids and jugulars, with at times a cyanotic condition of the face and attacks of dyspnca, but no headache. She had been getting out of health for a few months, and had been away for change; but, on returning home, was found to be in the above condition, and excessively wasted, so that it was necessary to place her on a water-bed for some four weeks. 